\title{
FEMINICÍDIO E A FORMAÇÃO CONTINUADA DE POLICIAIS CIVIS NA BAHIA: QUESTÕES E REFLEXÕES
}

\author{
Adriana Araujo dos Santos ${ }^{1}$ \\ Marilene Santos Lima Pereira ${ }^{2}$
}

\section{Resumo}

Este artigo apresentará alguns conceitos importantes para a compreensão da pesquisa realizada. $\mathrm{O}$ estudo teve como objetivo compreender o fenômeno do feminicídio a partir de estudo da percepção dos profissionais da Polícia Civil lotados em delegacias de Salvador. Para tanto foram utilizados questionários com os profissionais de segurança pública que trabalhavam nas duas delegacias tomadas como lócus da pesquisa. A ideia era a partir do questionário, ter uma visão e posteriormente fazer o mapeamento das percepções dos policiais civis acerca do fenômeno do feminicídio. O estudo foi guiado pela pesquisa quanti-qualitativa. Foi eleita essa metodologia com base nas demandas apresentadas pela própria pesquisa ao longo do estudo dos dados e da própria escrita do relatório da dissertação.

Palavras- Chave: Feminicídio. Formação Continuada. Policiais Civis.

\begin{abstract}
This article will present some important concepts for understanding the research carried out. The study aimed to understand the phenomenon of femicide based on a study of the perception of Civil Police professionals working in police stations in Salvador. For this purpose, questionnaires were used with public security professionals who worked in the two police stations taken as the locus of the research. The idea was based on the questionnaire, to have a vision and then to map the perceptions of civil police officers about the phenomenon of femicide. The study was guided by quantitative-qualitative research. This methodology was chosen based on the demands presented by the research itself throughout the study of data and the writing of the dissertation report.
\end{abstract}

Keywords: Femicide. Continuing Education. Civil Police.

\section{Introdução}

Este artigo é advindo de estudo realizado em dissertação de mestrado. Parte dele representa diálogo entre o que conhecemos enquanto notícias, perceções, leituras, mas tambémresulta das experiências profissionais vividas pela autora ao longo seu labor. O desejo de estudarcomo tema central o feminicídio não

\footnotetext{
${ }^{1}$ Mestra em Ciências da Educação pela Facultad Interamericana de Ciencias Sociales - FICS, em Assunção-Paraguai. Email: adriaraujos@outlook.com

${ }^{2}$ Doutoranda em Ciências da Educação pela Facultad Interamericana de Ciencias Sociales - FICS, em Assunção-Paraguai. Email: mari.bela92lima@gmail.com
} 
deve ser encarado apenas como uma pesquisa para a aquisição de um título acadêmico. Representa, antes de qualquer coisa, a denúncia da necessidade de reconhecemos o direito inalienável à vida que todo e qualquer sujeito tem. $\mathrm{A}$ cada ocorrência de feminicídio no mundo perdemos não só uma mulher, mas uma mãe, uma filha, uma companheira, uma pessoa com sonhos, crenças, desejos, opções, uma força de trabalho, enfim: uma cidadã que pelo mais alto grau de violência teve interrompida a sua vida e consequentemente interrompe-se todos os outros direitos.

Muitas descobertas foram surgindo ao longo do estudo. Uma das mais importantes foi perceber que embora seja o feminicídio um fenômeno mundial e crescente nos últimos anos, ao analisar o banco de teses e dissertações da CAPES, ficou evidente que havia poucos estudossobre o feminicídio. O estado da arte se mostrou fundamental para desvelar esse dado. Diante desse resultado, foram feitas algumas indagações que serviram de inspiração para a escrita da dissertação. Dentre estas questões tem: Por que os estudos sobre feminicídio são tão pequeninos, já que se trata de fenômeno social recorrente? Quais as premissas que impedem ouinviabilizam tais estudos? Por que a sociedade se cala frente a tal construção social?

Tais perguntas embora servissem como vetor para a escrita, continuam a ecoar na menteda autora e servem como base para a percepção de como a nossa sociedade ainda compreende a violência letal contra a mulher. Assim, este artigo trará aspectos conceituais de categorias analíticas abordadas no texto dissertativo e que foram fundamentais para a compreensão do fenômeno estudado. Destas categorias destaca-se: Educação, Feminicídio, formação continuada. Na sequência serão apresentados alguns dados importantes sobre a pesquisa realizada junto aos colaboradores. Por fim destacamos algumas considerações sobre a escrita do texto e as descobertas e sugestões que podem vislumbrar caminhos para um melhor atendimento de mulheres que busquem a segurança pública.

\section{A Educação que conhecemos e os nossos papeis sociais na busca de mudanças}

A educação deve ser compreendida como um fenômeno que extrapola os 
espaços educacionais: escolas, colégios, universidades, faculdades, centros acadêmicos, etc. educação é fenômeno que ocorre em diferentes espaços sócias (casa, escola, rua, campo de futebol, supermercados, lojas, igrejas e outros). Sendo este um fenômeno presente em qualquer espaço, se torna imperativa a necessidade de compreensão por parte de cada um de nós da importância que tem as nossas ações.

Segundo a Lei 9394 de 20 de dezembro de 1996, Lei de Diretrizes e Bases da EducaçãoNacional (LDB),

Art. 1ํ A educação abrange os processos formativos que se desenvolvem na vida familiar, na convivência humana, no trabalho, nas instituições de ensino e pesquisa, nos movimentos sociais e organizações da sociedade civil e nas manifestações culturais.

Como fica evidente no Art. $1^{\circ}$ da Lei que rege a educação no Brasil, o ato educativo é aberto e não se refere apenas as aprendizagens escolares. É importante que as famíliascompreendam seu papel enquanto agentes educadores, que a sociedade possa também perceber que existe uma parte do processo educativo que ocorre a partir das relações sociais que são estabelecidas nas mais simples atividades do dia a dia.

Ainda segundo a CF de 1988, em seus Art. 205,

A educação, direito de todos e dever do Estado e da família, será promovida e incentivada com a colaboração da sociedade, visando ao pleno desenvolvimento da pessoa, seu preparo para o exercício da cidadania e sua qualificação para o trabalho.

Assim, podemos afirmar com segurança que a educação se processa em diferentes espaços e com diferentes sujeitos. As pessoas (crianças, adolescentes, jovens e idosos) estão imersos num processo constante de educação. A cultura também é responsável por essa moldura.

Segue ainda a referida Lei destacando no $\S 1^{\text {a }}$ do mesmo artigo que a educação escolar deve ocorrer preferencialmente em espaços escolares e destacando: "a educação escolar deverá vincular-se ao mundo do trabalho e à prática social" (BRASIL, 1996, p.1).

Sendo a escolarização organizada, pensada e vinculada as práticas sociais e ao mundo do trabalho se faz necessário que os conteúdos, as atividades e sobretudo as vivências nos espaços escolares possam tomar o ambiente natural e 
social em que os sujeitos vivem como referência para as aprendizagens da tradição e da cultura letrada.

Brandão (2007) em seu livro O que é educação, destaca que não se trata de algo estanque que se processa em um único ambiente (a escola) e da mesma forma em todas as escolas. Ao contrário o autor acredita que a educação é algo vasto, conforme afirma a própria LDB.

\begin{abstract}
A educação existe onde não há a escola e por toda a parte podem haver redes e estruturas sociais de transferência de saber de uma geração a outra, onde ainda não foi sequer criada a sombra de algum modelo de ensino formal e centralizado. Porque a educação aprende com o homem a continuar o trabalhoda vida. A vida que transporta de uma espécie para a outra, dentro da história da natureza, e de uma geração a outra de viventes, dentro da história da espécie, os princípios através dos quais a própria vida aprende e ensina a sobreviver e a evoluir em cada tipo de ser. (BRANDÃO, 2007, p.13).
\end{abstract}

É possível perceber, a partir da citação de Brandão que a educação é transmitida pelas gerações e que estas, independentemente da existência de um espaço físico demarcado, denominado escola lograrão êxito na transmissão de saberes. A educação é um ato político e como tal deve se comprometer com a mudança social e com a autonomia dos sujeitos, na compreensão de Paulo Freire (1921-1997). Na concepção freireana, no ato de educar, educando e educador aprendem juntos. Contudo, isso não exclui a compreensão da autoridade do educador que tem que está baseada na sua maior experiência e formação acadêmica.

A Hannah Arendt (2005, p. 7) em seu ensaio intitulado A crise na Educação, afirma que "A educação é o ponto em que decidimos se amamos o mundo o bastante para assumirmos a responsabilidade por ele". Ao afirmar que temos responsabilidade sobre o mundo quando pensamos em educação, Arendt destaca a importância do ato educativo e como ele pode transformar o mundo, seja para o bem ou para o mal.

O confronto de valores (acadêmicos e do senso comum) pode ser possibilitado a partir da perspetiva da Educação em Direitos Humanos. Esta representa sobretudo a possibilidade de reflexão sobre uma educação verdadeiramente de defesa incondicional dos direitos individuais e coletivos. Ao avaliarmos mais cuidadosamente a constituição Federal de 1988, veremos que os Direitos Humanos são a base de sustentação da Carta Magna. 
Ao refletir sobre os direitos percebemos que a pessoa humana, independente das suas orientações ou classe social, tem direitos humanos, uma vez que nasceram com estes. Segundo as Diretrizes Nacionais de Educação em Direitos Humanos (DNEDH), a cultura da Educação em Direitos Humanos pode se constituir em ferramenta de transformação social com vista a uma sociedade mais justa. Considera ainda essa mesma diretriz que a educação é um instrumento fundamental para o fomento da EDH.

A Educação em Direitos Humanos tem um caráter permanente e sua concepção reflexiva, autoral e colaborativa para com a sociedade, sendo imprescindível a ação cidadã dos sujeitos. A compreensão da Educação em Direitos Humanos na contemporaneidade serve de forma inequívoca à uma necessidade de percepção de como a história e os movimentos sociais se organizaram para a reconfiguração de determinados aspectos da sociedade. Candau afirma que:

A educação em direitos humanos na América Latina é uma prática jovem (...) Começa a se desenvolver coincidentemente com o fim de um dos piores momentos da repressão política na América latina e conquista certo nível de sistematização na segunda metade da década e dos 80 . (2001, p. 63).

Em se tratando de uma nascente discussão, se faz necessária a sua divulgação e afirmação num contexto de políticas públicas voltadas para a compreensão e aplicação das legislações em que o Brasil se compromete e reconhece as diferentes violações dos Direitos Humanos. Nestas legislações, o país assevera a necessidade de ajuste de conduta frente as diferentes violações existentes no país, incluído o feminicídio, fenômeno estudado nestetrabalho.

Considera como importante forma de divulgação e propagação dos ideias da Educaçãoem Direitos Humanos o próprio ato educativo. Nesse sentido, não se apresentam apenas para a educação escolarizada, mas também os processos educativos que ocorrem na cidade, no bairro, no trabalho, nos transportes, nas feiras livres, etc.

Essa forma de concepção da EDH representa sobretudo, uma convocação da sociedade civil a assumir sua responsabilidade enquanto compatrícia numa democracia. É preciso entender porque as violações ocorrem, criando ambiente dialógico e sobretudo reflexivo para aescrita de uma nova história. 


\section{O feminicídio mais que um conceito uma triste realidade}

O Feminicídio se apresenta enquanto uma das violações dos Direitos Humanos, a principal delas: o direito à vida. A violação desse direito interrompe todos os outros e sobretudo, quando não julgado e punido os transgressores há a construção de uma cultura da impunidade e da normalidade dos delitos cometidos.

Sabemos que nas sociedades patriarcais, a mulher é vista como sujeito que está abaixo dos homens. Isto posto, o pai, o marido, o namorado, o irmão, o chefe, todos têm direitos sobre aquela propriedade. Essa forma de pensar criou uma atmosfera de negação da autonomia e da legitimidade de voz entre as mulheres, ecoando enquanto uma história de longa duração no que diz respeito a essa mentalidade.

Segundo relatório da ONU, publicado em novembro de 2019,

No mundo todo, em países ricos e pobres, em regiões desenvolvidas e em desenvolvimento, um total de 50 mil mulheres são assassinadas todo ano porcompanheiros atuais ou passados, pais, irmãos, mulheres, irmãs e outros parentes, devido ao seu papel e a sua condição de mulheres [...]. (ONUDD, 2018, s.p).

Segue ainda afirmando que em todo o mundo, incluindo países ricos e pobres, independentemente do nível de desenvolvimento, 50 mil mulheres são assassinadas todos os anos por homens que eram seus pais, companheiros atuais ou passados, irmãos, mulheres, irmãs e outros parentes, devido ao seu papel e a sua condição de mulheres. Assegura ainda que o lar, por esse motivo se torna um lugar perigoso para as mulheres.

A Organização das Nações Unidas alerta os alarmantes dados do feminicídio no mundo. Destaca que seis mulheres são vítimas de feminicídio a cada hora. Segue ainda afirmando que isso é resultado de uma cultura machista difundida na sociedade. Afirma ser a educação e formação de meninos e meninas na prevenção ao feminicídio uma importante ferramenta de mudança.

É nesse sentido que a EDH deve atuar, numa perspectiva de formação dos sujeitos para a compreensão do seu papel enquanto cidadão ativo na sociedade e defensor dos Direitos Humanos. No Brasil, temos uma realidade muito difícil de ser enfrentada. Segundo estudo da ONU, a América Latina apresenta altos índices de feminicídio e o Brasil está entre um dos países em que 
mais ocorre esse tipo de fenômeno.

Vivemos uma grave e complexa realidade no que diz respeito aos atos de violência contra as mulheres. Os dados internacionais reforçam essa infeliz realidade. Segundo a Organização das Nações Unidas (ONU) 70\% das mulheres em todo o mundo sofrerão espancamentos, estupros, abusos ou mutilações, pelo menos uma vez ao longo da sua vida (BUZI, 2014).

No caso da América Latina, a Organização Pan-Americana de Saúde (OPAS) afirma que a violência de gênero está generalizada em toda a América Latina e nos países do Caribe. Realizou-se pesquisa com mulheres e entre $17 \%$ e $53 \%$ das destas relataram ter sofrido violência física ou sexual, em algum momento por um parceiro íntimo. (ORGANIZACÍON PANAMERICANA DE LA SALUD, 2014).

Para caracterizar a realidade do Brasil, segundo o Instituto Brasileiro de Geografia e Estatística (IBGE) a violência doméstica é a responsável pela maior parte dos atendimentos registrados na Central Telefônica de Atendimento à Mulher da Secretaria de Políticas das Mulheres (SPM). A violência contra a mulher não pode ser pensada num contexto de etnia, classe social, nível de escolarização e outros atributos de ordem cultural ou biológica.

Os dados da SPM apontam que no ano de 2009, do total de 401.729 chamadas, 52,3\% foram relatos de violência contra a mulher. Dentre esses: lesões corporais leve, grave e gravíssima, inclusive de tentativa de homicídio e assassinato (feminicídio). No ano de 2010 , foram registrados $68,7 \%$ casos central telefônica 180. Comumente, o agressor era o companheiro, marido, namorado da vítima (IBGE, 2010).

Lei 13.104 de 09 de março de 2015, alterou o Código Penal brasileiro, incluindo o feminicídio como qualificador do crime de homicídio. Esta Lei não emoldura, de forma indiscriminada como feminicídio qualquer assassinato de mulheres. Inclusive, o fato de muitossetores sociais (os conservadores, sobretudo) desconhecerem o conteúdo da lei possibilitou o seu questionamento, bem como a negação da necessidade de existência de uma lei específica para tratar dos homicídios de mulheres vítimas de violência em decorrência de sua condição feminina. O feminicídio serve efetivamente qualificar um homicídio nos casos descritosanteriormente.

O feminicídio pode ser pensado também enquanto termo político, ideológico 
e legal cuja função principal é a reflexão sobre essa forma de violação do mais importante direito: a vida.Podemos afirmar que o feminicídio representa a expressão máxima da violência experimentada pelas mulheres nas diferentes partes do mundo.

\section{Achados da Pesquisa: feminicídio e saberes de profissionais de segurança Pública}

As pesquisas realizadas em qualquer campo do conhecimento devem servir ao progresso da sociedade, seja na perspectiva do desenvolvimento humano, social, político, cultural, dentreoutras. A pesquisa realizada e defendida aqui sobre o feminicídio foi significativa para desvelar aspectos relevantes para a sociedade com vistas à compreensão do fenômeno estudado.

Assim, serão apresentados alguns achados que sinalizam para a reflexão do papel da Educação em Direitos Humanos, o feminicídio e formação continuada de profissionais de segurança pública. Dessa forma, serão apresentados aqui os dados levantados ao longo do estudo e que, de alguma forma contribuem para uma retomada da reflexão da formação profissional no contexto de continuidade.

Os estudos que seguem foram catalogados a partir de questionário apresentado para os profissionais colaboradores; o instrumento de coleta de dados foi organizado no sentido de caracterizar o perfil econômico, social, educacional e profissional dos profissionais de segurança pública.

O desenvolvimento da pesquisa aplicada se deu em delegacias sediadas em Salvador, Estado da Bahia. Foram aplicados questionários em duas unidades: Delegacia Especial de Atendimento à Mulher (DEAM), unidade sediada no bairro de Brotas, e no Departamento de Homicídios e Proteção à Pessoa (DHPP), que fica situado no Bairro da Pituba.

As DEAMs são delegacias especializadas no atendimento de mulheres em condição deviolência. Trata-se de uma atividade desenvolvida pelas polícias civis cuja função é a defesa, investigação e posterior enquadramento legal de crimes que envolvem mulheres na condição de vítima. Para além das funções desempenhadas nas DEAMs em todo o território nacional, a partir da emergência da Lei Maria da Penha, Lei de 7 de agosto de 2006, estas delegacias também passaram a realizar outras atividades voltadas à proteção das mulheres. 
O Departamento de Homicídios e Proteção à Pessoa, segundo lócus em que ocorreu a aplicação da pesquisa, tem como função a investigação de homicídios dolosos com e sem autoria.

Ambos os lócus têm como função primária a proteção à vida e cumprir o que prevê a Constituição Federal de 1988, alicerçados nos princípios irrevogáveis da defesa dos Direitos Humanos.

Dentre os achados da pesquisa tem-se entre a maioria dos entrevistados sujeitos do sexo feminino, com filhos, casados, com renda familiar acima de cinco salários mínimos. No que diz respeito a escolarização todos tem ensino médio, tendo também uma significativa parcela que acessaram 0 ensino superior completo, sendo que $30 \%$ ingressou no ensino superior, mas evadiu. As discussões que envolvem aspectos ligados à cultura machista e à violência contra a mulher remontam à própria história da sociedade.

Uma das coisas mais importantes a serpensada é que tanto a cultura machista quanto o feminicídio são produções culturais dasociedade e podem ser desconstruídas em processos educativos constantes, como o que é previsto no Plano Nacional de Educação em Direitos Humanos. Nessa segunda etapa dapesquisa, tentamos construir questões que potencializassem a compreensão do fenômeno nasociedade e como tais dados podem fortalecer propostas de empoderamento da mulher na sociedade.

A primeira pergunta dessa segunda seção do questionário foi: a nossa sociedade é machista? As possibilidades de respostas estavam direcionadas para sim, não ou às vezes. A análise dos questionários apresentara como resultado a existência do machismo na sociedade.

\section{Sociedade machista?}

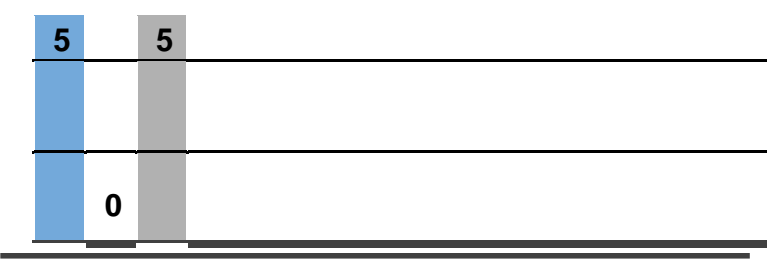

- Sim $\square$ Não $\square$ As vezes 
Há inequivocamente o reconhecimento de que a sociedade brasileira é machista e istose revela também em diferentes dados apresentados pelo Atlas da violência e pelas pesquisasdo IPEA no que diz respeito à distribuição de renda, equiparação salarial, funções sociaisdesempenhadas, ocupações em cargo de chefia e nos poderes municipais, estaduais e federais.

Sabemos que as representações coletivas (DURKHEIM), as representações sociais (MOSCOVICl), bem como as construções de identidades são forjadas no fazer social de cadagrupo. Estes fazeres terminam por produzir o que vemos sobre nós mesmos e sobre o outro. Foineste contexto que oferecemos no questionário a seguinte pergunta: você considera que anatureza do homem é violenta? Para esta questão obtivemos as respostas: $40 \%$ dos participantes da pesquisa responderam sim, que a natureza do homem é violenta. $20 \%$ dos pesquisados afirmaram que a natureza do homem não é violenta e os $40 \%$ restantes afirmam que às vezes a natureza do homem pode ser violenta. Em dados gráficos temos:

Natureza do homem

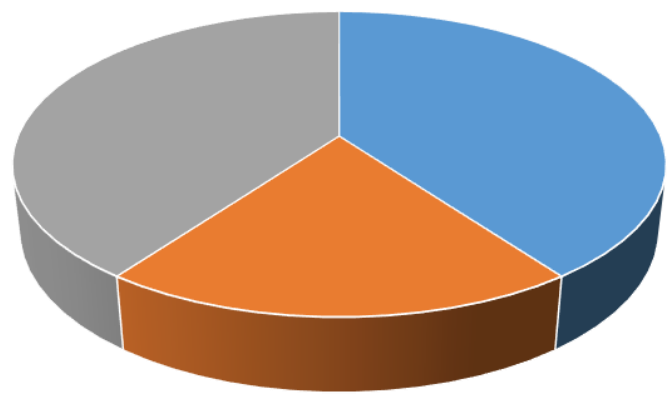

- Violenta

As análises das respostas apresentadas oferecem importantes aspectos a serem pensados tanto do ponto de vista da educação quanto aos aspectos históricos, além da constatação da construção social da pseudo ideia de que existe uma natureza violenta ligada à questão do sexo, sobretudo o masculino.

Percebemos que $80 \%$ dos respondentes acreditam que existe de fato uma construção biológica para a violência dos homens. É importante perceber a relevância dessa indagação em virtude da revelação da necessidade de intervenção social na reelaboração de outras compreensões da natureza. Ao ser pensada a questão da natureza violenta, estamos transferindo um atributo 
puramente social a questões biológicas.

Os discursos sobre educação em direitos humanos, a Constituição Federal Brasileira de 1988, destacam a igualdade de todos independente de gênero, religião, sexo, classe social, dentre outros atributos construídos culturalmente. Urge, portanto, a necessidade de reelaboração de valores sociais e culturais que possam fazer emergir outras referências que tomem a natureza do homem como natureza humana e que reconheça que a violência é um constructo social. Como tal, pode ser reelaborada, repensada e transcendida para uma outra perspectiva.

Outro aspecto importante de ser analisado é perceber como pensamos e refletimos as nossas atitudes (no seio do lar, nos espaços públicos e privados, nos ambientes de aprendizageme também no trabalho) nos diferentes espaços em que estamos inseridos. Isto posto, devemos tomar os processos formativos como primordiais na transformação, mudança e mediação das ações dos sujeitos em todos os espaços e momentos em que cada um esteja.

$\mathrm{Na}$ contramão da questão apresentada anteriormente, foi feita a seguinte pergunta: você acredita que o comportamento muitas vezes violento do homem é resultado de uma aprendizagem social? As respostas foram a seguintes: 10\% afirmam que a violência do homemnão é resultado de aprendizagem social; $60 \%$ dos respondentes afirmam que sim, a violência que os homens apresentam em diferentes contextos é resultado de apreensão social e os $30 \%$ restantes afirmam que às vezes o comportamento violento é resultante sim de uma construção social.

A representação gráfica se desenha da seguinte forma:

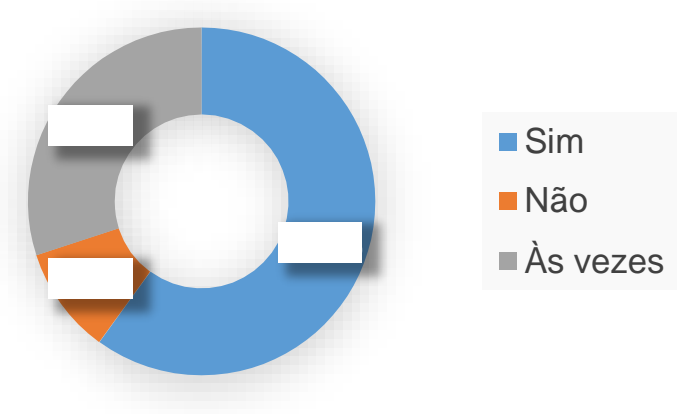

As respostas a esta questão mais uma desvelam uma importante informação sobre a questão da violência e sua referência em relação ao sexo masculino. A análise gráfica possibilita afirmar com segurança que $90 \%$ (se considerada as 
respostas sim e às vezes) dos respondentes afirmam que há uma construção social para a questão da violência do homem.

Ao cruzar os dados apresentados, podemos perceber como há um deslocamento da linha condutora das respostas, quando comparada à questão anterior (sobre a natureza do violenta dohomem), e esta (sobre a construção social dessa natureza). Verifica-se, ao confrontar essas duas questões, que os respondentes não seguem a linha biológica da natureza violenta, tampouco a linha da construção social da violência entre os homens.

Mais uma vez é indispensável reconhecer a relevância de ações voltadas à desconstrução de valores equivocados sobre o ser homem e ser mulher, sobre os papéis sociais e a construção de gênero, bem como a ideia de violência e a questão dos gêneros.

Ainda em busca de informações relevantes sobre as questões da cultura machista, foi perguntado: você acredita que uma educação voltada para a desconstrução de uma possível cultura machista pode favorecer novas atitudes de homens e mulheres num futuro próximo, evitando inclusive novos feminicídios? Das respostas colhidas, tem-se: $90 \%$ dos respondentes acreditam que uma educação voltada para a desconstrução da cultura machista possibilitaria atitudes diferentes daquelas que experimentamos na conjuntura atual. Os 10\% restante afirmaram que, mesmo com uma educação voltada para a desconstrução do machismo, não haveria mudança alguma.

Depois de traçar o perfil dos colaboradores da pesquisa, buscou-se no mesmo questionário entender os discursos sobre o feminicídio e prática profissional. Os profissionais em todos os campos do conhecimento precisam passar por formações continuadas e deaperfeiçoamento com vistas a uma melhor oferta dos serviços prestados. Sabe-se também que no caso da segurança pública torna-se imperativa a necessidade de aprimoramento constante, face a natureza do serviço e da própria dinâmica social.

Os discursos sobre o feminicídio se fortalecem no Brasil a partir da década de 1990. Além de categoria sociológica, o feminicídio foi reconhecido com legislação específica como crime. A lei 13.104/15 alterou o código penal, incluindo o feminicídio como mais uma modalidade de homicídio qualificado, isto, evidentemente quando o autor do crime o fizer contra a mulher em virtude da sua condição feminina. 
Atualmente, os agentes de segurança pública (sejam eles responsáveis constitucionalmente pela segurança preventiva ou investigativa/repressiva) devem atentar não apenas para conhecer os fenômenos sociais que envolvem a dinâmica do crime, mas principalmente compreender e buscar formas de proteger a sociedade e guardar o bem maior: avida.

Foi tomando como base estas questões que foram elaboradas as perguntas neste bloco, pensado para perceber as questões que implicam no fazer profissional em segurança pública e a questão do feminicídio. Assim perguntou-se: em sua prática profissional, você se considera preparado para lidar com a prevenção ao feminicídio?

As respostas obtidas podem ser assim expressas no gráfico abaixo:

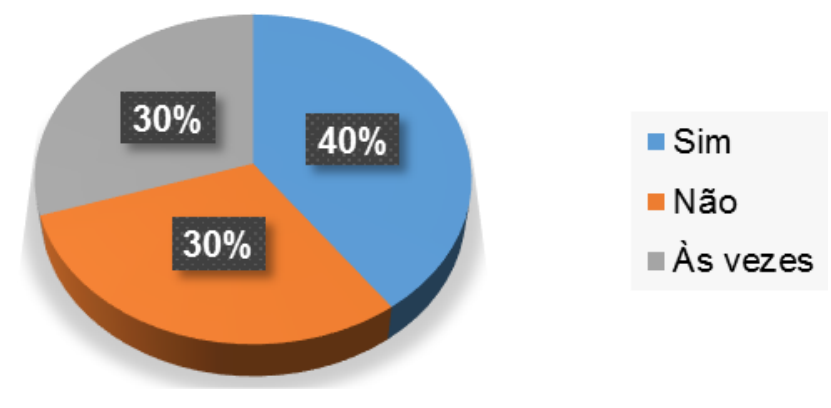

Das respostas apontadas pelos participantes, podemos aferir que a maioria acreditar estar preparado para atuar de forma preventiva, evitando os casos de feminicídio. É importante perceber que essa ação num contexto de delegacia representa atender as mulheres em situação de violência, fazer os devidos encaminhamentos e sobretudo encontrar e aplicar a lei aos autores e possíveis feminicidas. É imperativo destacar que cerca de 70\% dos colaboradores afirmam não saber lidar com a situação questionada ou às vezes saberem como atuar no caso questionado.

O questionário apresentou mais uma pergunta que relaciona o assunto do feminicídio com as experiências profissionais dos respondentes: na sua experiência profissional, ao atender mulheres vítimas de violência doméstica é possível identificar vulnerabilidade e possível propensão da vítima a uma situação de feminicídio?

As respostas sugeridas foram: sim, que recebeu $50 \%$ das respostas, não com apenas $10 \%$ das respostas e às vezes, $40 \%$ das respostas apresentadas. Numa linguagem gráfica temos: 


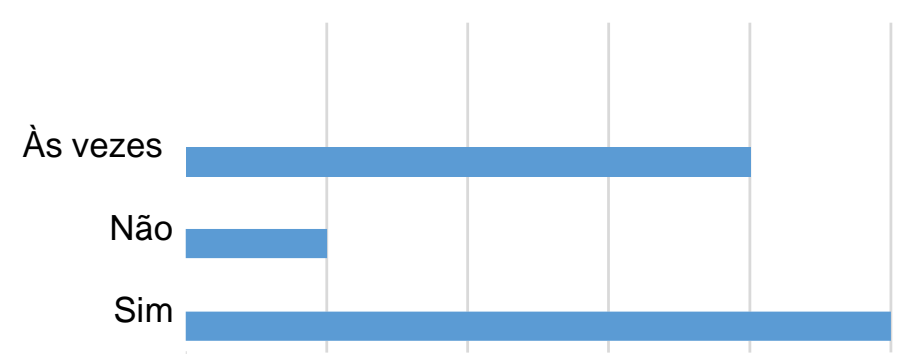

Ao afirmar que estão preparados para lidar de forma preventiva com o feminicídio, os informantes destacam que nas suas realidades e experiências é possível reconhecer uma situação de violência contra a mulher que possa de alguma forma evoluir para o feminicídio. Apenas $10 \%$ dos respondentes afirma não se sentir preparado(a) para lidar de forma preventivacom o feminicídio.

A pergunta imediata foi ainda na busca da compreensão da relação feminicídio e atuação dos profissionais de segurança que colaboraram com este estudo. Dessa forma interpelou-se o seguinte: Você julga importante ações de formação inicial e continuada para profissionais de segurança pública para atuação na prevenção ao feminicídio?

Para as respostas foram oferecidas as alternativas sim ou não. Os respondentes afirmaram que são importantes ações de formação inicial e continuada para os profissionais de segurança pública atuarem preventivamente no combate ao feminicídio. Apenas $10 \%$ dos respondentes avalia essa possibilidade como não relevante. Num desenho gráfico temos:

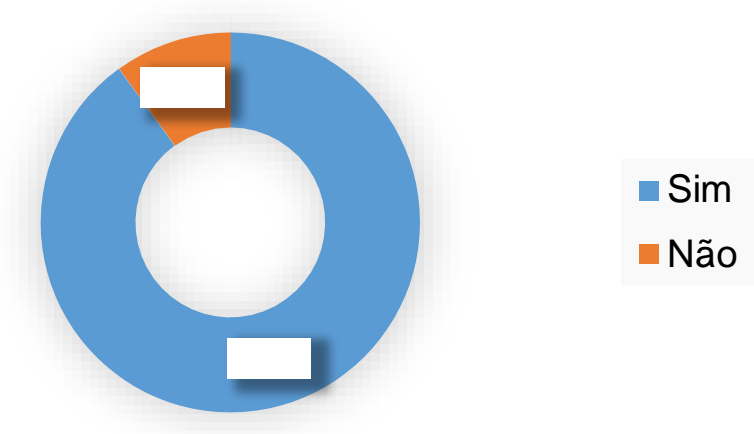

As formações inicial e continuada representam importantes ferramentas para o exercício profissional e isso possibilita que num momento inicial, por exemplo, o futuro operador de segurança pública, no caso avaliado neste texto, a partir de um 
conjunto de habilidades adquiridas, possa oferecer um serviço que atenda de forma satisfatória o sujeito assistido. No caso da formação continuada, possibilita o repensar profissional, buscando aprendizagens novas que contribuirão na sua carreira profissional e pessoal. Em todas as etapas da vida profissional dos sujeitos nas diferentes áreas, a formação continuada é indicada e, no caso da segurança pública, isso deve ser potencializado pela própria função exercida pelas polícias.

A formação continuada não deve ser pensada apenas com o objetivo de atender as demandas verificadas no trabalho. É preciso ampliar os horizontes no que diz respeito a esta possibilidade de aprendizagem. É indispensável que uma formação possa colaborar com as questões profissionais, mas também possa oferecer possibilidade de reconhecimento de si e dooutro, bem como do seu papel social enquanto sujeito histórico.

Ainda tentando entender a percepção do grupo colaborador do estudo no que diz respeitoà formação continuada, foi inquirido: qual dos fatores você julga mais relevante para uma formação continuada? Como sugestão de respostas tem-se: a) conhecer a legislação; b) entender o fenômeno social do feminicídio, bem como políticas públicas sobre proteção e segurança de mulheres; c) conhecer dados estatísticos sobre o feminicídio.

Esta pergunta visava a mapear se os respondentes compreendiam o fenômeno do feminicídio com um viés jurídico, sociológico ou estatístico. As respostas foram as seguintes: $100 \%$ dos participantes afirmaram ser mais relevante entender o fenômeno social do feminicídio, bem como políticas públicas sobre proteção e segurança de mulheres.

Os fenômenos sociais são compreendidos enquanto objetos de estudo da sociologia. Estes devem ser percebidos como relacionados às práticas sociais e à vida dos homens e mulheres em sociedade. A compreensão de um fenômeno social envolve diferentes aspectos como: a) a experiência dos sujeitos com o tema em questão; b) a formação familiar; c) grau de escolarização; d) a geração em que o sujeito cresceu.

Torna-se indispensável destacar que as transformações pelas quais a sociedade passa interferem diretamente na forma de agir e pensar dos sujeitos e, junto com o movimento de mudança social, podemos perceber mudanças pessoais. Uma mudança que vem sendo percebida na sociedade e que as 
pessoas precisaram se adaptar e reconhecer como legítima está relacionada à emergência da Constituição Federal de 1988. Por essa Constituição ficou evidenciada uma série de garantias individuais e coletivas que antes desse período não estavamem vigor. No caso específico da CF de 1988, que é um conjunto de leis, esta é resultante de movimentos sociais que reclamavam direitos não reconhecidos, mas necessários para o exercício da cidadania no Brasil.

Certamente o conhecimento do fenômeno e das políticas públicas atrelados a um maior embasamento da legislação, bem como o conhecimento de dados estatísticos sobre o tema em questão, possibilite o reconhecimento da gravidade da situação em que se encontra o Brasil como um todo e a Bahia em especial.

A questão seguinte representa uma tentativa de perceber o nível de conhecimento dos respondentes em relação à lei do feminicídio. Assim, foi perguntado se você conhece a Lei no 13.104, de 9 de março de 2015? As respostas sugeridas foram: a) sim, totalmente; b) sim, parcialmente; c) já ouvi falar; d) não. Os achados da pesquisa para esta questão proposta foram:

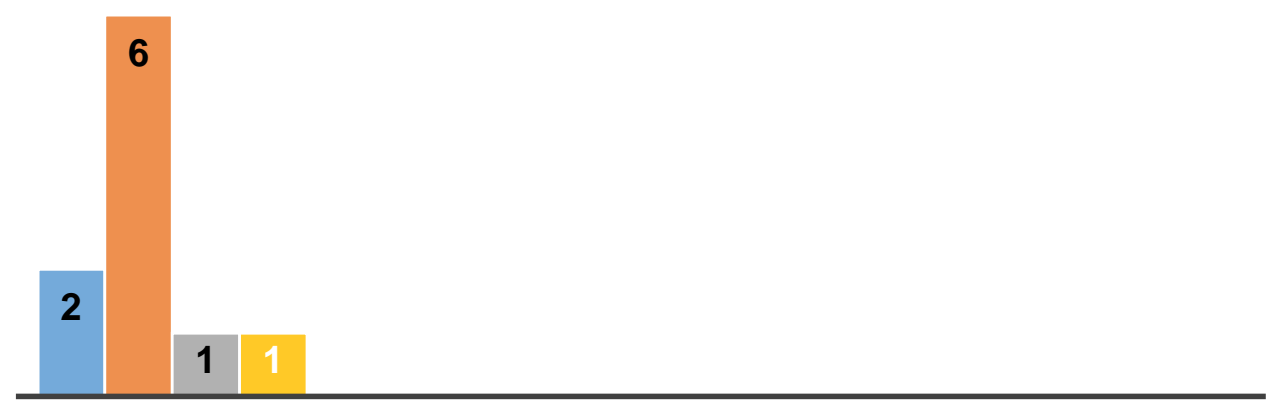

- Sim totalmente $\quad$ - Parcialmente $\backsim$ Já ouviu falar $\backsim$ Desconhece

A ampla maioria dos colaboradores da pesquisa afirmam conhecer a Lei $n^{\circ}$ 13.104, de 9 de março de 2015. Por esta Lei tem-se alterado "o art. 121 do Decreto-Lei ํㅡ 2.848, de 7 de dezembro de 1940 - Código Penal, para prever o feminicídio como circunstância qualificadora do crime de homicídio, e o art. $1^{\circ}$ da Lei no 8.072, de 25 de julho de 1990, para incluir o feminicídio no rol dos crimes hediondos". (BRASIL, 2015, s.p).

O conhecimento da Lei anteriormente apresentada possibilita 0 entendimento jurídico eas sanções a serem aplicadas aos sujeitos que comentem esse tipo de crime. Trata-se de indispensável forma de conhecimento sobre o 
tema.

A última pergunta a ser proposta no questionário foi: você conhece os dados sobre o feminicídio no mundo, no Brasil e na Bahia? As respostas sugeridas foram: a) sim, totalmente;

b) sim, parcialmente; c) já ouvi falar e d) não. Encontraram-se as seguintes respostas:

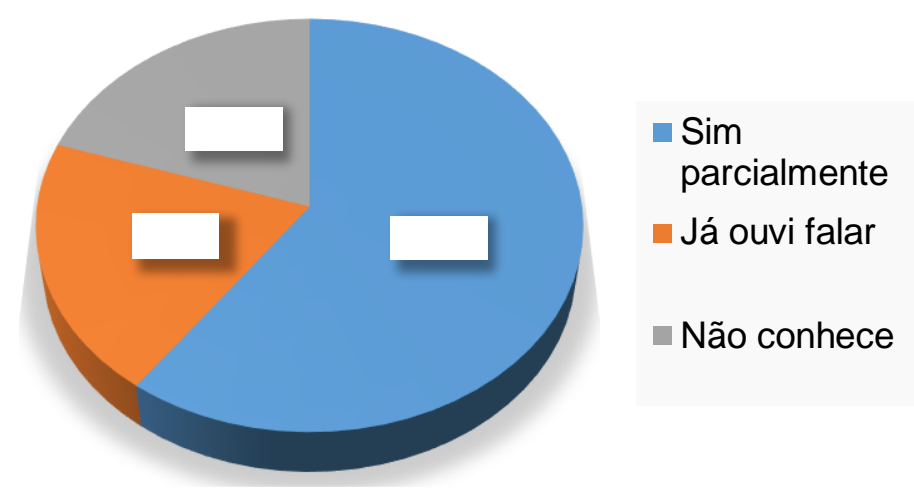

Os dados relativos ao feminicídio no mundo tem se ampliado, conforme revela o relatório da ONU em 2018. Os dados mostram que todos os dias aproximadamente 137 mulheres são mortas em todo o mundo por familiares ou parceiros. Esses dados refletem a urgência e importância de políticas de valorização e proteção das mulheres em todo o globo.

No caso do Brasil, segundo dados do IPEA, a partir da publicação do Atlas da Violência, há destaque para o crescimento dos homicídios femininos em 2017. Segundo os dados apresentados, são cerca de 13 assassinatos/dia. No ano de 2018, foram registrados 4.936 casos de homicídios de mulheres (feminicídios) em todo o país. Segundo os pesquisadores, é o maior número registrado desde o ano de 2007. O Atlas da Violência (2019, p.35) destaca [...]

[...] crescimento expressivo de 30,7\% no número de homicídios de mulheres no país durante a década em análise (2007-2017), assim como no último ano da série, que registrou aumento de 6,3\% em relação ao ano anterior. Entre 2007 e 2017 houve aumento de 20,7\% na taxa nacional de homicídios de mulheres, quando a mesma passou de 3,9 para 4,7 mulheres assassinadas por grupo de 100 mil mulheres. Nesse período, houve crescimento da taxa em 17 Unidades da Federação.

O feminicídio na Bahia nos três primeiros meses de 2019 teve aumento, se comparado ao mesmo período de 2018, segundo dados da Secretaria de Segurança 
Pública da Bahia. Destaca-seque apesar dessa realidade, foi registrada queda de 32,6\% em casos de estupros, o que representa menos 61 casos se comparado ao mesmo período do ano anterior.

Dessa forma, podemos afirmar que o feminicídio representa um fenômeno social importante de ser estudado e isso requer um trabalho conjunto de todos os setores sociais, nos diferentes espaços. É imperativo que a Bahia e o Brasil possam superar os dados estatísticos apresentados e dessa forma garantir o que prevê a Constituição Federal de 1988.

\section{Considerações}

O direito à vida se apresenta na Constituição Federal de 1988 como fundamental e inegociável. Nesse sentido, a emergência dos homicídios contra as mulheres representa a violação deste direito e consequentemente a finalização ou violação de todos os outros direitos. Segundo dados da Secretaria Nacional de Segurança Pública do Distrito Federal, a cada dois segundos uma mulher é agredida no Brasil. Ainda segundo a Comissão de Direitos Humanos do Senado Federal "84\% dos crimes contra mulheres ocorrem dentro das residências e que essedetalhe dificulta o trabalho repressivo da polícia". Segue ainda afirmando que cerca de "60\% dos casos, [de agressão estão relacionados] ao sentimento de posse do homem sobre a mulher,o que ocasiona ciúme excessivo e brigas".

Os dados anteriormente apresentados destacam a relevância da discussão central deste artigo. O feminicídio neste trabalho foi tomado enquanto categoria sociológica e fenômeno socialmente construído. A construção social do feminicídio passa por uma série de interpretações e valoração amparadas naquilo que a sociedade toma como referência, bem como a partir de valores tradicionais que são repassados pela sociedade. Isto posto, é possível afirmar assertivamente que os papeis sociais que temos de homem e mulher são resultantes daquilo que vivemos nos diferentes espaços educativos.

Foi a partir de tal compreensão que foi pensado o objetivo geral do estudo primário quedeu origem a este artigo; assim estabeleceu-se a seguinte premissa: compreender o fenômeno do feminicídio a partir de estudo da percepção dos profissionais da Polícia Civil lotados em delegacias de Salvador. Consideramos que este objetivo foi atendido de forma satisfatória, uma vez que a metodologia 
empregada buscava identificar os saberes e fazeres profissionais (ligados à percepção) dos policiais civis respondentes no que diz respeito ao feminicídio. Foi tomada como referência a perspectiva da educação profissional (na formação inicial e continuada destesprofissionais) e seus conhecimentos sobre o tema.

Para melhor mapeamento das informações necessárias à produção deste relatório, foram traçados os seguintes objetivos específicos: a) discutir a partir da teoria conceitos ligados a feminicídio, educação, Educação em Direitos Humanos e formação continuada. Consideramoseste objetivo alcançado uma vez que foram estudadas, a partir de bibliografia os conceitos pontuados no objetivo analisado.

Os dados apresentados nos questionários são reveladores de aspectos a serem pensadosquanto à construção social da ideia de que a violência masculina é atributo biológico e não umaconstrução social.

Outras revelações apresentadas nos questionários possibilitam afirmar que são importantes, necessárias e urgentes ações de formação continuada destinadas aos profissionais de segurança pública como um todo, tomando como referência aspectos do fenômeno do feminicídio, bem como estudos da Lei 13.104 de 2015.

\section{Referências}

ARENDT, H. A crise na educação. In: Entre o passado e o futuro. Tradução Mauro W. Barbosa. 5. ed. São Paulo: Perspectiva, 2005.

BAHIA. Plano Estadual de Educação em Direitos Humanos. Comitê Estadual de Educação em direitos Humanos (2009). Secretaria da Justiça, Cidadania e Direitos Humanos.

Disponível em: http://www.dhnet.org.br/dados/pp/edh/estaduais/pedh_ba_2010.pdf. Acessoem: 25out19.

BENEVIDES, Maria Victoria. Educação em Direitos Humanos: de que se trata? Palestra de abertura do Seminário de Educação em Direitos Humanos, São Paulo, 18/02/2000. A autora agradece a importante contribuição do Prof. Fábio Konder Comparato.

BRASIL. Constituição da República Federativa do Brasil de 1988.

Disponível http://www.planalto.gov.br/ccivil_03/constituicao/constituicaocompilado.htm. Acesso em:13out19. 
Educação e daJustiça. Disponível em:

file:///C:/Users/Acer/Downloads/plano_nacional.pdf. Acesso em: 23out19.

BRANDÃO, Carlos Rodrigues. O que é educação. (Coleção Primeiros Passos) 49a reimpr. da

1. ed. de 1981. São Paulo: Brasiliense, 2007.

BRASIL. Senado Federal. Comissão Parlamentar Mista de Inquérito sobre Violência contra aMulher

(Relatório Final,(CPMI-VCM, 2013). https://www12.senado.leg.br/institucional/omv/entenda-a-violencia/pdfs/relatoriofinal-da- comissao-parlamentar-mista-de-inquerito-sobre-a-violencia-contra-asmulheres.

Secretaria de Direitos Humanos da Presidência da República. Educação em Direitos Humanos: Diretrizes Nacionais. Brasília: 2013

Lei 9394/1996. Lei de Diretrizes e Bases da Educação Nacional. Disponível em: http://www.planalto.gov.br/ccivil_03/leis/19394.htm. Acesso em: 05set19.

Lei 9394/1996. Lei de Diretrizes e Bases da Educação Nacional. Disponível em: http://www.planalto.gov.br/ccivil_03/leis/19394.htm. Acesso em: 05set19.

Secretaria de Direitos Humanos da Presidência da República. Educação em Direitos Humanos: Diretrizes Nacionais. Brasília: 2013

CANDAU, Vera Maria. Experiências de educação em direitos humanos na América Latina: o caso brasileiro. Cadernos NOVAMÉRICA. Rio de Janeiro: NOVAMÉRICA, n. 10, setembro de 2001.

. Educação em direitos humanos: principais desafios. Rio de Janeiro: 2005.

FREIRE, P. A Educação na Cidade. São Paulo: Cortez, 1996.

FREIRE, P. Pedagogia da Autonomia - saberes necessários à prática educativa. São Paulo:Paz e Terra, 2003.

GARCIA, C. M. A formação continuada: novas perspectivas baseadas na investigação sobre o pensamento do professor. In nóvoa, António (Coord.). Os professores e sua formação. 3. ed.Lisboa: Dom Quixote, 1999. p. 51-76.

MORIN, Edgar. Os sete saberes necessários à educação do futuro / Edgar Morin; tradução de Catarina Eleonora F. da Silva e Jeanne Sawaya; revisão técnica de Edgard de Assis Carvalho.- 2. ed. - São Paulo: Cortez ; Brasília, DF : UNESCO, 2000

NÓVOA, A. A formação tem que passar por aqui: as histórias de vida no projeto Prosalus. In: Nóvoa A. e Finger, M. (orgs). 0 método (auto) biográfico e a 
formação. Lisboa: Ministérioda Saúde, 1988. p. 109-130.

ONU. ONU Mulheres. Disponível em: http://www.onumulheres.org.br/onumulheres/sobre-a-onu-mulheres/.

Assembleia Geral da ONU aprovou a Resolução 16/1

Observatorio de Igualdad de Género de América Latina y el Caribe. Nota para la Igualdad № 27: El feminicidio, la expresión más extrema de la violencia contra las mujeres. Disponível em: https://oig.cepal.org/es/notas/nota-la-igualdadno-27-feminicidio-la-expresion-mas-extrema-la-violencia-mujeres.

OPAS BRASIL. Formação Continuada para o Sistema Nacional de Defesa Civil. https://www.paho.org/bra/. Acesso em: 20out19. 